\title{
$\widehat{A}$ Madridge \\ madridge Journal of Case Reports and Studies
}

Interconnecting Scientific World

Case Report

Open Access

\section{Anaphylactic Reaction to Intraoperative Intravenous Mannitol: A Case Report}

\author{
Ankur Mehra ${ }^{\star}$, Anil Mishra and Malvika Gupta \\ Senior Resident, Department of Anaesthesia and Critical Care, Maulana Azad Medical College and Lok Nayak hospital, Bahadur Shah Zafar \\ Marg, New Delhi, India
}

\section{Article Info}

*Corresponding author:
Ankur Mehra
Senior Resident
Department of Anaesthesia and Critical Care
Maulana Azad Medical College and
Lok Nayak Hospital
India
E-mail: dr.ankurmehra@gmail.com

Received: October 4, 2018

Accepted: October 15, 2018

Published: October 23, 2018

Citation: Mehra A, Mishra A, Gupta M. Anaphylactic Reaction to Intraoperative Intravenous Mannitol: A Case Report. Madridge J Case Rep Stud. 2018; 2(2): 88-89.

doi: $10.18689 /$ mjcrs-1000122

Copyright: (c) 2018 The Author(s). This work is licensed under a Creative Commons Attribution 4.0 International License, which permits unrestricted use, distribution, and reproduction in any medium, provided the original work is properly cited.

Published by Madridge Publishers

\begin{abstract}
A 24 year old female, diagnosed with right middle cerebral artery aneurysm was posted for aneurysmal clipping. After uneventful induction of anaesthesia, on starting mannitol infusion patient developed high airway pressures within minutes. After ruling out common conditions, a diagnosis of anaphylactic reaction to mannitol was made. Surgery was postponed and after initial stabilization patient was shifted and managed in ICU. Although a rare entity, intraoperative anaphylactic reaction to mannitol should be kept in mind by anaesthesiologist.
\end{abstract}

Keywords: Mannitol; Anaphylaxis; Neurosurgery; Intraoperative anaphylaxis

\section{Key Messages}

Despite mannitol's widespread use, there is a possibility of hypersensitivity to intravenous mannitol administration. The physician should be aware that hypersensitivity reactions may occur and be prepared to handle such adversities.

\section{Introduction}

Anaphylaxis is a severe, life-threatening allergic reaction mostly caused by classical IgE-mediated hypersensitivity [1]. Various foods, drugs, insect stings and latex are commonly reported to cause anaphylactic reactions in atopic individuals.

Mannitol, a non-toxic and non-metabolizable osmotically active compound is administered as a therapeutic agent inmany clinical situations such as for prophylaxis against acute renal failure, differential diagnosis of acute oliguria andreduction of cerebrospinal and intraocular fluidpressures [1]. The main effect of mannitol is increasing the osmolality of blood, causing the osmotic equilibrium to make fluid flow into the vessels. As mannitol is an inert hapten not having any reactive groups, it cannot form conjugates with macromolecular carriers by itself. Hegde et al proposedthat the Schiffbase intermediate of D-mannose with proteins (formed by Maillard reaction in vivo) bearing D-mannitoyl groups might be responsible for eliciting a mannitol-specific IgE response [2].

Although hypersensitivity to mannitol is rarely documented, this case report describes a patient who experienced a serious allergic reaction after the administration of intravenous mannitol.

\section{Case History}

A 24 year old ASA class 1 female diagnosed as having right middle cerebral artery aneurysm was scheduled to undergo aneurysmal clipping. There was no significant 
finding in pre-anaesthetic check up. Lab investigations were within normal limits. The patient was taken up in the operation theatre, routine monitors attached, two wide bore intravenous cannulas secured.

The patient was induced with fentanyl $(2 \mu \mathrm{g} / \mathrm{kg})$, propofol (2 mg/kg), and vecuronium $(0.1 \mathrm{mg} / \mathrm{kg})$. After bag and mask ventilation for 3 minutes, she was intubated with an appropriate size endotracheal tube. The patient was put on pressure control mode. The patient was catheterised with Foley's catheter. After checking for preoperative antibiotic sensitivity, injection ceftriaxone $1-\mathrm{g}$ was given intravenously. Central line was secured via a subclavian approach. Mannitol was started via slow IV infusion. Within few minutes the ventilator showed high airway pressures and delivery of a very low tidal volume. Pleural rupture during central line insertion leading to pneumothorax was suspected. Patient was started on $100 \%$ oxygen and taken on hand ventilation. On auscultation of chest, bilateral equal air entry was found to be equal although ronchi were heard. Bilateral percussion sound was normal. Findings did not collaborated with our diagnosis of pneumothorax. In the meanwhile patient developed hypotension (BP 78/42 mm Hg) and tachycardia (HR 138 per minute) along with flushing of face and trunk. Diagnosis of anaphylactic reaction was made. One litre crystalloid was rushed via central line. Mannitol infusion was stopped. Patient was put in a Trendelenburg position. A bolus of 100 microgram intravenous adrenaline was given and adrenaline infusion started at $1 \mathrm{micogram} / \mathrm{kg} / \mathrm{min}$ and titrated to maintain blood pressure within normal range. Injection dexamethasone $8 \mathrm{mg}$, hydrocortisone $200 \mathrm{mg}$ and pheniramine $20 \mathrm{mg}$ were given to the patient.

Once the patient was hemodynamically stable, infusion of fentanyl (1 $\mu \mathrm{g} / \mathrm{kg} / \mathrm{hr}$ ) and vecuronium (1 $\mu \mathrm{g} / \mathrm{kg} / \mathrm{min}$ ) was started and the patient was shifted to the Intensive Care Unit (ICU) for further management. She was managed symptomatically, infusion of adrenaline was continued to maintain mean blood pressuse above $60 \mathrm{mmHg}$ and hydrocortisone $200 \mathrm{mg}$ TDS was given. After 24 hours patient developed facial edema, however her chest condition improved. She was extubated on third day after edema had subsided, chest was cleared of ronchi and patient no more required ionotropic support. Patient was shifted to the ward after observing for few more hours in ICU.

The patient was taken up again for the same procedure the following day. Intraoperatively standard protocol was followed as before and injection furosemide and 3\% normal saline was used to decrease intracranial pressure instead of mannitol. The surgery went uneventful.

\section{Discussion}

Mannitol is a white crystalline sugar also named mannite or manna sugar [3]. Mannitol has an inert structure and is conventionally not considered to have immunogenic covalent properties [4]. Venkatesh and Hegde have proposed D-mannitol can act as bivalent hapten leading to cross linking with cell bound specific $\lg \mathrm{E}$, thus induce a true $\lg \mathrm{E}$-mediated reaction [2]. In an aqueous solution D-mannitol mostly exists as a cyclic form, however, a small fraction of it exist as acyclic form. It is proposed that D-mannose forms Schiff base conjugates with amino groups of proteins which acts as a sensitizer for D-mannitol. Once mannitol-specific IgE antibodies sensitize an individual, D-mannitol can act as a univalent elicitor, resulting in an anaphylactic reaction [5].

Complications like pulmonary congestion following mannitol infusion are well documented and may occur with any osmoticdiuretic given in sufficient dosage to a susceptible patient [6]. However, an anaphylactoid reactionto a simple carbohydrate such as mannitol is rare [6]. To the best of our knowledge there are very few case reports regarding hypersensitivity reaction after mannitol administration [4-9].

Although we considered the possibility of an adverse reaction to another drug, none could be found as the culprit. The only other medication suspected was the ceftriaxone. However, it was given after preoperative sensitivity testing and the reaction did not occur when the drug was repeated. The mannitol that was used was a commercial preparation from a previously unopened bottle. The temporal relationship of the patient's reaction with mannitol infusions suggests a strong causal relationship.

Anaesthesiologists should be aware of this unusual but important reaction to this commonly used and generally innocuous medication.

\section{Conflict of interest: None}

\section{References}

1. Hegde VL, Venkatesh YP. Anaphylaxis to excipient mannitol: evidence for an immunoglobulin E-mediated mechanism. Clin Exp Allergy. 2004; 34(10): 1602-9. doi: 10.1111/j.1365-2222.2004.02079.x

2. Hegde VL, Venkatesh YP. A hypothesis for the mechanism of immediate hypersensitivity to mannitol. Allergol Intern. 2003; 34: 165-70. doi: 10.1046/j.1440-1592.2003.00295.x

3. Calogiuri G F, Muratore L, Nettis E, Casto A M, Di Leo E, Vacca A. Immediate-typehypersensitivity reaction to Mannitol as drug excipient (E421): a case report. Eur Ann Allergy Clin. Immunol. 2015; 47(3): 99-102.

4. Siahaan $A M$, Fithrie A. Acute hypersensitivity to mannitol: a case report IOP Conf. Ser.: Earth Environ. Sci. 2018; 125: 012222.

5. Spaeth GL, Spaeth EB, Spaeth PG, LucierAC. Anaphylactic reaction to mannitol. Arch Ophthalmol. 1967; 78(5): 583-584. doi: 10.1001/ archopht.1967.00980030585004

6. Lamb JD, Keogh JAM. Anaphylactoid reactionto mannitol. Canad Anaes Soc J. 1979; 26: 435-436. doi: 10.1007/BF03006461

7. Findlay SR, Kagey-Sobotka A, LichtensteinLM. In vitro basophil histamine release induced bymannitol in a patient with a mannitol-induced anaphylactoidreaction. J Allergy Clin Immunol. 1984; 73(5): 578-583.

8. McNeill IY. Hypersensitivity reaction tomannitol. Drug Intell Clin Pharm. 1985; 19(7): 552-553.

9. Biro $P$, Schmid $P$, Wüthrich $B$. A life-threateninganaphylactic reaction following mannitol. Anaesthesist. 1992; 41(3): 130-133. 